\title{
Effects of Transactional and Transformational Leadership Styles on Innovation: Knowledge Sharing as Mediator and Gender as Moderator Case of French Knowledge-intensive Firms
}

\author{
Berraies Sarra, Bchini Belgacem, Zine EL Abidine Syrine and Mejri Tarek
}

\begin{abstract}
This research aims to highlight the impact of transformational and transactional leadership styles on exploitative and exploratory innovation, the mediating effect of knowledge sharing and the moderating effect of gender in these links. An empirical study was conducted on 122 top executives in French knowledge-intensive firms. The partial least square method highlighted that the transformational leadership fosters knowledge sharing and exploitative and exploratory innovations and that transactional leadership is not linked to both types of innovation and knowledge sharing. Results revealed also that gender moderates the link between transformational leadership and exploitative innovation and exploratory innovations. This research provides a better understanding of the contribution of the leadership styles on knowledge sharing and the two types of innovation. It can help managers of knowledge-intensive companies to highlight key elements that may improve the firms' innovation.
\end{abstract}

Keywords - Transformational leaders, transactional leaders, knowledge sharing, exploration, exploitation, gender, knowledge intensive companies, France.

\section{INTRODUCTION}

Firms operate nowadays in an uncertain and turbulent environment in which the key success factor is innovation (Drucker, 1994).To innovate, firms can focus on the skills and knowledge that they already know and their routines to achieve exploitative innovation or acquire new skills and knowledge and explore new perspectives in order to generate exploratory innovation (March, 1991). Many authors like March (1991) and Berraies and Zine El Abidine (2019) stressed that firms should mix between exploitative and exploratory innovation and be ambidextrous to achieve optimal performance. In this line, Leadership is highlighted by numerous authors as a key success factor for firms. Berraies and Bchini (2019) and Berraies and Zine El Abidine (2019) have focused on the effect of leadership on the two types of innovation. In the

Berraies Sarra, Assistant Professor, Higher Institute of Management of Tunis, Tunis University, Laboratory ARBRE, Tunisia.

Bchini Belgacem and Zine EL Abidine Syrine, Higher Institute of Management of Tunis, Tunis University, Laboratory ARBRE, Tunisia.

Mejri Tarek, University Paris-Descartes, Paris. perspective of studies that have studied ambidexterity, the goal of this research is to highlight the effect of two leadership styles: transformational leadership and transactional leadership on exploitative and exploratory innovations. This work deepened the analysis by testing the mediating role of knowledge sharing and the moderating role of the gender of the leader in these relationships. The research questions are:

Do the transformational and transactional leadership styles foster the exploitative and exploratory innovations?

Does the knowledge sharing mediate these relationships?

Does the gender of the leader mediate these links?

The importance of this research resides first in highlighting the effects of two styles of leadership namely the transformational and the transactional styles on two types of innovation namely 'exploitative innovation' and 'exploratory innovation' and the mediating role of knowledge sharing. Indeed, little research shed light on the relationship between these variables. Second, this research offers an interesting perspective as we have tested the moderating effect of gender in the relationship between leadership styles, knowledge sharing and types of innovation. A review of the literature shows that no research has tested the moderating role of the leaders' gender regarding the links tested. Also, the context of knowledge intensive companies is particularly interesting for this research as these firms tend to integrate both exploration and exploitation innovation projects (Ohehmichen et al., 2017) and need a different style of leadership than other types of companies (Donate and de Pablo, 2014). Furthermore, Cavaliere et al. (2015) outlined that the leadership style is the most essential organizational factor that boosts knowledge sharing within knowledge intensive firms.

The conceptual model defined through a thorough review of the literature is tested empirically on a sample of 122 managers working in French Knowledge-intensive firms. A quantitative analysis is performed via a questionnaire integrating, among other things, the scales of measurements of the different variables of the research. A partial least square method is used to test the hypotheses. 


\section{LITERATURE REVIEW}

\section{A. Leadership styles and innovation}

Many authors emphasized the role of the leadership in innovation (Berraies and Bchini, 2019; Berraies and Zine El Abidine, 2019; Garcia-Morales et al., 2008). In particular, these researchers focused on the transactional and transformational leadership styles as determinants of innovation. Transformational leaders intellectually stimulate subordinates, individually considerate them and encourage them to achieve organizational objectives, to accept the organizational mission and to do extra efforts beyond what is expected from them (Bass, 1985). Transactional leadership materializes a leader-subordinates' relation of exchange that is based on authority and in which leaders rewards or punish subordinates regarding their efforts and tasks accomplished.

Garcia-Morales et al. (2008) outlined that the transformational leadership is more likely to foster innovation than the transactional leadership. Berraies and Bchini (2019) found that transformational leadership positively affects exploratory and exploitative innovations, whereas the transactional leadership has a positive effect on exploitative innovation and not on exploratory innovation. The same result is generated by the research of Berraies and Zine El Abidine (2019). Yadav (2015) stressed that transactional leadership is likely to provide constructive feedback that may improve routines and may foster exploitative innovation but hinder exploratory innovation. Thus, we expect that transformational leadership has a positive effect on exploitative innovation (H1) and exploratory innovation (H2). Transactional leadership has a positive effect on exploitative innovation (H3) and a negative effect on exploratory innovation (H4)..

\section{B. Mediating role of knowledge sharing}

Transformational leaders stimulate explicit and tacit knowledge transfers within individuals and within the organization (Argyris and Schon, 1996). The tacit knowledge is considered more strategic than the explicit one and allows the company to obtain sustainable competitive advantages and improvements in organizational performance (Garcia-Morales et al., 2007). Indeed, transformational leaders have important characteristics that enable them to stimulate people to build good communication networks and a spirit of trust, allowing the transmission and sharing of knowledge (Senge, 1990, Slater and Naver, 1995). These characteristics are the charisma, the inspiration, the intellectual stimulation, and the individualized consideration of the employees (Bass, 1999, Bass and Avolio, 2000).

In contrast to transformational leaders, transactional leaders rely on the use of rewards in the form of pay or recognition to encourage employees and establish leadership positions. As their name implies, transactional leadership is based on the exchange and constant negotiation between the work done and the counterpart. This system creates stability and efficiency in achieving short-term goals. In addition, transactional leaders are geared towards day-to-day business optimization also expecting individuals to share their insights within the company.Nonaka and Takeuchi (1995) emphasized that leadership optimizes knowledge sharing within firms.

Thus, we expect that transformational leadership and transactional leadership has a positive effect on knowledge sharing (H5 and H6).

Knowledge sharing is a major strategic issue for firms. Knowledge has an economic value and is analyzed as a strategic resource, factor of innovation and creativity, allowing the company to anchor itself in the competitive universe (Crié, D., 2003). In this line, a large number of authors considered knowledge sharing as a fundamental lever through which employees can contribute to the application of knowledge and innovation within firms (Jackson et al., 2006; Nonaka and Takeuchi, 1995; Wang, S. and Noe, R. A., 2010).

Because of the potential benefits of knowledge sharing, many organizations have invested significant time and money into knowledge management initiatives, including the development of knowledge management systems that use advanced technology to facilitate collection. storage and dissemination of knowledge. These findings were subsequently corroborated by a large number of authors such as Kim et al., (2017), Florea et al., (2013). Wang et al. (2017) and Kim and Lee (2013).Knowledge sharing leads to seeking opportunities to get off the beaten tracks and innovative behaviors ( $\mathrm{Zu}$ and $\mathrm{Mu}, 2016)$. It develops the capacity to create and transform ideas into innovations. When employees share knowledge, innovation is enhanced.

Nonaka and Takeuchi (1995) stressed that by knowledge sharing, employees develop their learning capacities and may improve existing products and process and elaborate new products and process. These researchers outlined the value of knowledge sharing to exploitative and exploratory innovations. Berraies et al. (2015) revealed also that the knowledge sharing leads to both exploitative and exploratory innovations.

Thus, we expect that knowledge sharing has a positive effect on exploitative innovation (H7) and on exploratory innovation (H8).

Knowledge sharing may mediate the relationships between transformational and transactional leadership styles and exploitative and exploratory innovations (H9, H10, H11 and H12).

\section{Moderating role of gender}

The existence of gender differences has been recognized in social interactions, which play an important role in the workplace. Social role theory provides a conceptual basis for explaining gender differences in social relations (Abukhait et al.,, 2018). According to this theory, different social expectations for women and men establish social norms that emphasize the control and competition for men in relation to cooperation, friendship and intimacy for women in the world social interactions. Therefore, Abukhait et al., (2018) expect gender differences in knowledge sharing processes and in the management of the company. Lin (2006) indicated that women are more willing to share their knowledge because they have to 
overcome traditional barriers to career advancement.

In addition, sexist stereotypes tend to value male leadership as positive or effective, while female leadership is generally downgraded (Powell et al., 2002, Powell, 1999). In fact, in the larger organization, all management positions are held by men, women have less access to knowledge resources in the workplace (Diaz et al., 2007, Kim et al., 2016). Thus, as noted by the researchers (Ayman and Korabik 2010, Ayman et al., 2009), gender plays an implicit role in the culture of the workplace.

Thus, based on the dominant perceptions of gender differences in workplace hierarchies and access to resources, we expect that they may be differences between women and men regarding the impact of leadership styles on knowledge sharing and innovation (H13, H14, H15, H16, H17 and H18).

\section{METHODS}

A quantitative research was carried out on a sample of top executives of French knowledge-intensive firms via questionnaires. Among 200 questionnaires distributed, we received 122 valid questionnaires. All the respondents are highly educated. 73 are men and 49 are women. The majority of firms consists of medium firms who have between 50 and
499 employees. We measured exploitative and exploratory innovation through the 14 items developed by Jansen et al. (2008). Transformational and transactional leadership styles were measured through the 32 items of the Multifactor Leadership Questionnaire (MLQ-5x) conceptualized by Bass and Avolio (1995). Knowledge sharing was measured the 4 items developed by Lin (2007). A five-point Likert scale was used for all the items.

We conducted a principal component analysis via SPSS software using the Varimax rotation method that generated one-dimensional measurement scale for each type of innovation and knowledge sharing and a multidimensional scale for transformational and transactional leadership. Table 1 shows for final structure the normality and the validity of each construct generated by the SMART PLS 3 software. The Cronbach alpha of all constructs is higher than 0.7 (Hair et al., 2014). Table 1 highlights that the average variance extracted is greater than 0.5 for all constructs (Hair et al., 2014). Also, the discriminant validity was verified as the square roots of the AVE of all constructs are bigger than the correlations between constructs (Hair et al., 2017).

TABLE I: THE ARRANGEMENT OF CHANNELS

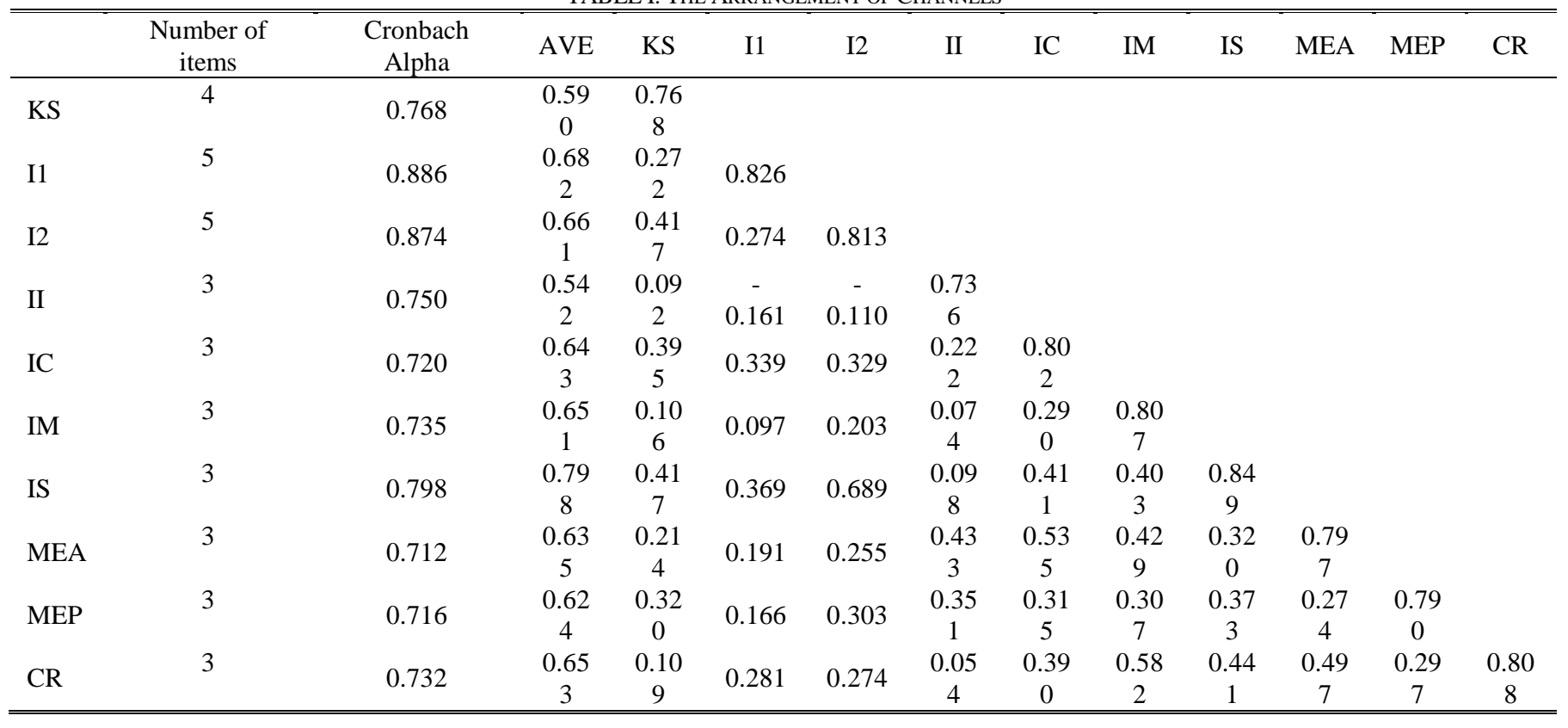

KS: Knowkedge sharing, I1: exploitative innovation, I2: Exploratory innovation, II: Idealized influence, IC: Individualized consideration, MEA: management by exception active, MEP: Management by exception passive, IM: Inspirational motivation, CR: Contingent rewards, IS: Intellectual stimulation

\section{RESULTS}

A Partial Least Square method was performed through the Smart PLS software 3 to test the research hypotheses.

The R2 index of the dependent variables is respectively 0.419 for exploratory innovation, 0.168 for exploitative innovation and 0.197 for knowledge sharing and is therefore greater than 0.1 (Fernandes, 2012). Table 3 show that knowledge sharing positively and significantly influence exploratory innovation $(\beta=0.191, \mathrm{p}<0.05)$ and do not have a significant effect on exploitative innovation $(\mathrm{p}>0.05)$. H8 is thus confirmed and $\mathrm{H} 7$ is rejected. A multi-group analysis is also used to test the moderating role of gender. Results show 
that the effect of knowledge sharing on exploitative innovation is not significant for men and women. Also, the impact of knowledge sharing on exploratory innovation is significant for women and not for men. Transactional leadership is not significantly linked to exploratory innovation, exploitative innovation and knowledge sharing ( $>>0.05)$. These effects are not significant for men and women. Thus, H3, H4 and H6 are rejected. Transformational leadership has a positive and significant impact on exploitative innovation $(\beta=0.314$, $\mathrm{p}<0.05)$, exploratory innovation $(\beta=0.670, \quad \mathrm{p}<0.001)$ and knowledge sharing $(\beta=0.398, \mathrm{p}<0.05)$. Therefore, H1, H2 and H5 are confirmed. In this line, the impact of transformational on exploitative innovation is significant for women and not for men, while the effect of this type of leadership on exploratory innovation and knowledge sharing is significant for men and women. According to the Welch-Satterthwait test, the gender moderates the link between transformational leadership and exploitative innovation. $\mathrm{H} 13$ is confirmed. All other hypotheses regarding the moderating role of gender are rejected.

TABLE II: RESULTS OF DIRECT LINKS

\begin{tabular}{|c|c|c|c|c|c|c|c|}
\hline \multirow{2}{*}{$\begin{array}{l}\text { Independent } \\
\text { variable }\end{array}$} & \multirow[t]{2}{*}{ Dependent variable } & \multicolumn{2}{|c|}{ Total sample } & \multicolumn{2}{|c|}{ Women } & \multicolumn{2}{|c|}{ Men } \\
\hline & & $\boldsymbol{\beta}$ & $\mathbf{p}$ & $\beta$ & $\mathbf{p}$ & $\boldsymbol{\beta}$ & $\mathbf{p}$ \\
\hline \multirow[t]{2}{*}{$\begin{array}{c}\text { Knowledge } \\
\text { sharing }\end{array}$} & $\begin{array}{l}\text { Exploitative } \\
\text { innovation }\end{array}$ & 0.120 & $\begin{array}{c}0.27 \\
2\end{array}$ & 0.230 & 0.062 & -0.245 & 0.347 \\
\hline & $\begin{array}{l}\text { Exploratory } \\
\text { innovation }\end{array}$ & 0.191 & $\begin{array}{c}0.03 \\
1\end{array}$ & 0.261 & 0.010 & 0.064 & 0.761 \\
\hline \multirow{3}{*}{$\begin{array}{l}\text { Transformation } \\
\text { al leadership }\end{array}$} & Knowledge sharing & 0.398 & $\begin{array}{c}0.01 \\
9\end{array}$ & 0.451 & 0.000 & 0.347 & 0.000 \\
\hline & $\begin{array}{l}\text { Exploitative } \\
\text { innovation }\end{array}$ & 0.314 & $\begin{array}{c}0.03 \\
9\end{array}$ & 0.421 & 0.011 & 0.219 & 0.294 \\
\hline & $\begin{array}{l}\text { Exploratory } \\
\text { innovation }\end{array}$ & 0.670 & $\begin{array}{c}0.00 \\
0\end{array}$ & 0.621 & 0.000 & 0.797 & 0.000 \\
\hline \multirow{3}{*}{$\begin{array}{l}\text { Transactional } \\
\text { leadership }\end{array}$} & Knowledge sharing & 0.062 & $\begin{array}{c}0.74 \\
4\end{array}$ & 0.049 & 0.819 & 0.082 & 0.828 \\
\hline & $\begin{array}{l}\text { Exploitative } \\
\text { innovation }\end{array}$ & 0.038 & $\begin{array}{c}0.82 \\
0\end{array}$ & -0.090 & 0.645 & 0.294 & 0.314 \\
\hline & $\begin{array}{c}\text { Exploratory } \\
\text { innovation }\end{array}$ & -0.207 & $\begin{array}{c}0.16 \\
2 \\
\end{array}$ & -0.190 & 0.247 & -0.210 & 0.548 \\
\hline
\end{tabular}

Note $\beta$ : standardized regression coefficient, C.R. : critical ratio, ${ }^{\text {ns }}$ : non significative

Table 3 highlights the findings for the mediating effects. A non-parametric boostrapping method was used in this perspective (Hair et al., 2014). The total effect of the independent variable on the dependent variable is tested (Hair et al., 2014). As such, transformational leadership is linked positively and significantly to exploitative and exploratory innovations. Although, transactional leadership styles is not linked to both types of innovation. Therefore, KS does not mediate these links. Furthermore, findings show that in the presence of the mediating variable, the links between transformational leadership and exploratory innovation and exploitative innovation are significant. Hair et al. (2014) recommend also the calculation of the variance accounted for (VAF). This index is inferior to $20 \%$ showing that there is no mediation effect of knowledge sharing in the link between transformational leadership and exploratory and exploitative innovations. Thus, H9, H10. H11 and 12 are rejected.

\begin{tabular}{|c|c|c|c|c|c|c|c|c|}
\hline Link & Mediator & $\begin{array}{l}\text { IV- } \\
\text { Mediator }\end{array}$ & $\begin{array}{c}\text { Mediator } \\
\text {-DV }\end{array}$ & Direct effect & $\begin{array}{c}\text { Indirect } \\
\text { effect }\end{array}$ & Total effect & $\begin{array}{l}\text { VAF } \\
(\%)\end{array}$ & $\begin{array}{c}\text { Results } \\
\text { for } \\
\text { mediation }\end{array}$ \\
\hline TR1-IN1 & & $0.398^{*}$ & $0.120^{\mathrm{ns}}$ & $0.314^{*}$ & 0.048 & $0.361^{*}$ & 13.29 & $\begin{array}{c}\text { No } \\
\text { mediation }\end{array}$ \\
\hline TR1-IN2 & $\mathrm{KS}$ & & $0.191^{*}$ & $0.670 * * *$ & 0.076 & $0.746^{* * *}$ & 10.18 & $\begin{array}{c}\text { No } \\
\text { mediation }\end{array}$ \\
\hline TR2-IN1 & & $0.062^{\mathrm{ns}}$ & $0.120^{\mathrm{ns}}$ & $0.038^{\mathrm{ns}}$ & 0.007 & $0.046^{\mathrm{ns}}$ & N/A & $\begin{array}{c}\text { No } \\
\text { mediation }\end{array}$ \\
\hline TR1- IN2 & & & $0.191 *$ & $-0.207^{\mathrm{ns}}$ & 0.012 & $-0.195^{\mathrm{ns}}$ & N/A & $\begin{array}{c}\text { No } \\
\text { mediation }\end{array}$ \\
\hline
\end{tabular}

Notes: IV: independent variable (Styles of leadership); DV: dependent variables (exploitative and exploratory innovations); IN1: exploitative innovation, IN2 : Exploratory innovation ; TR1 : Transformational leadership, TR2 : Transactional leadership, KS: knowledge sharing.

*** : $\mathrm{P}<0,001, *<0,05 ;{ }^{\mathrm{ns}}$ : non significative

$\mathrm{VAF}<20 \%$ : no mediation, $20 \% \leq \mathrm{VAF} \leq 80 \%$; partial mediation, $\mathrm{VAF}>80 \%$ : full mediation

N/A: According to Hair et al. (2014), the VAF cannot be calculated in these cases (Hair et al., 2014). 


\section{DISCUSSION AND CONCLUSION}

Results show that the effect of transformational leadership is more important on exploratory innovation than on exploitative innovation. This result corroborates the research of Berraies and Bchini (2019) and Berraies and Zine EL Abidine (2019). Transformational leaders foster changes and pushes employees to transform things, to do more that is expected to them, to be creative and to explore new perspectives more than focusing on improving routines. This style of leadership has also a positive and significant impact on knowledge sharing. Transactional leadership, on the other hand, hasn't a significant effect on exploitative innovation, exploratory innovation and knowledge sharing. This finding is consistent in part with the research of Berraies and Bchini (2019) who found that transactional leadership is not linked to exploratory innovation. But, this result infirms the results of the study of these authors who found that transactional leadership is linked to exploitative innovation. Knowledge workers in the knowledge intensive firms need a transformational leadership that may improve their creativity and respond to their intrinsic needs. A transactional leadership may has a negative effect on their motivation and hinder creativity and innovation.

Findings also show that knowledge sharing is associated positively and significantly to exploratory innovation but does not influences significantly exploitative innovation. The share of knowledge resulted from synergetic interactions may lead to creation of new knowledge (Nonaka and Takeuchi, 1995) and the discover of unfamiliar ideas that in turn may generate exploratory innovation.

As for moderating test, our results showed that 'gender' moderates the relationship between transformational leadership style, knowledge sharing and both types of innovation. The data analysis shows that women with a transformational leadership style have a greater influence than men having the same style on 'exploitative innovation' but men having the same style have a greater effect on 'exploratory innovation' than transformational women leaders. Female leaders with a transformational leadership style have a greater significant effect on knowledge sharing than men having the same style of leadership. As for transactional leadership style, men and women leaders with this style haven't an influence on the two types of innovation and on knowledge sharing.

Despite the lack of theoretical study on the difference between leaders male and female in knowledge sharing and innovation in its two types, exploitative and exploratory, we can mention that our results corroborate the ideas advanced by Abukhait et al., (2018) and Lin (2006).

\section{CONCLUSION}

This study demonstrates the importance of transformational and transactional leadership styles in fostering exploitative and exploratory innovations, taking into account the mediating effect of knowledge sharing and the moderating effect of gender. Based on a sample of 122 leaders of knowledge- intensive French companies, this article performs partial least squares to test the conceptual model and research hypotheses. The results show that transformational leadership is a strategic lever for knowledge sharing and innovation, both exploitative and exploratory. In contrary, transactional leadership is not related to both types of innovation and knowledge sharing. In addition, it is important to note that gender is a moderating factor in the relationship between transformational leadership and both types of innovation. Our article has both theoretical and empirical implications, in the sense that it enriches this field of research, which, despite the work done on this subject, requires further study and clarification. In addition, this research can help knowledge-intensive business leaders to identify key elements that can enhance innovation and encourage knowledge sharing within the organization.

\section{REFERENCES}

[1] M.R. Abukhait, S. Bani-Melhem, and R. Zeffane, (2018), « Empowerment, knowledge sharing and innovative behaviours : exploring gender differences », International Journal of Innovation Management, 23(1), 1950006. https://doi.org/10.1142/S1363919619500063

[2] C.Argyris, and D. A. Scho“ n (1996). Organizational Learning II: Theory, Method, and Practice. London: Addison-Wesley.

[3] B.M. Bass, (1999). 'Two decades of research and development in transformational leadership', European Journal of Work and Organizational Psychology, 8 (1), pp. 9-32. https://doi.org/10.1080/135943299398410

[4] B. Bass, and B. J. Avolio (2000). MLQ Multifactor Leadership Questionnaire Technical Report. Thousand Oaks, CA: Sage.

[5] D. Crié, (2003). « De l'extraction des connaissances au knowledge management », Revue française de gestion, 146(5), pp.59 à 79 . https://doi.org/10.1080/135943299398410

[6] B.M. Bass, (1985), Leadership and performance beyond expectation, New York: Free Press.

[7] B.M. Bass, B.M., and B.J. Avolio, (1995), MLQ Multifactor Leadership Questionnaire, Redwood City, CA: Mind Garden. https://doi.org/10.1080/135943299398410

[8] S. Berraies, and B. Bchini, (2019), "Effect of leadership styles on financial performance: mediating roles of exploitative and exploratory innovations: Case of Knowledge-intensive firms", International Journal of Innovation Management, 23(3), pp. 1950020/1-1950020/33. https://doi.org/10.1142/S1363919619500208

[9] S. Berraies, S. and S. Zine ElAbidine, (2019), « Do leadership styles promote ambidextrous innovation? Case of knowledge-intensive companies», Journal of Knowledge Management, In Press. https://doi.org/10.1108/JKM-09-2018-0566

[10] S. Berraies, M. Achour, and M. Chaher (2015), "Focusing the mediating role of knowledge management practices: How does institutional and interpersonal trust support exploitative and exploratory Innovation?", Journal of Applied Business Research, 31(4), pp.1479-1492. https://doi.org/10.19030/jabr.v31i4.9331

[11] V. Cavaliere, S. Lombardi, and L. Giustiniano (2015), "Knowledge sharing in knowledge-intensive manufacturing firms: An empirical study of its enablers", Journal of Knowledge Management, 19(6), pp.1124-1145. https://doi.org/10.1108/JKM-12-2014-0538

[12] J.M. Donate, and J.D.S. Pablo, (2014), "The role of knowledge-oriented leadership in knowledge management practices and innovation", Journal of Business Research, 68(2), pp.360-370. https://doi.org/10.1016/j.jbusres.2014.06.022

[13] P. Drucker, (1994), "The theory of business", Harvard Business Review, 72(5), pp.95-104.

[14] V. Fernandes, (2012), "Re-discovering the PLS approach in management science”, M@n@gement, 15(1),pp.101-123. https://doi.org/10.3917/mana.151.0102 
[15] V.J. Garcia-Morales, F.J. Lloréns-Montes, and A.J. Verdú-Jover, (2008), "The effects of transformational leadership on organizational performance through knowledge and innovation", British Journal of Management, 19(4), pp.299-319. https://doi.org/10.1111/j.1467-8551.2007.00547.x

[16] J.F. Hair, G.T.M., Hult, C. Ringle and M. Sarstedt (2014), A primer on partial least squares structural equation modeling (PLS-SEM), Sage Publications. https://doi.org/10.1108/EBR-10-2013-0128

[17] J.J.P. Jansen, G.George, V.A. Bosch, and H.W. Volberda (2008), "Senior team attributes and organizational ambidexterity: The moderating role of transformational leadership", Journal of Management Studies, 45(5), pp.982-1007. https://doi.org/10.1108/EBR-10-2013-0128

[18] S.E. Jackson, C.H. Chuang, E.E. Harden, Y. Jiang, \& J.M. Joseph (2006). Toward developing human resource management systems for knowledge-intensive teamwork. In J. M. Joseph (Ed.), Research in personnel and human resources management, 25. (pp. 27-70). Amsterdam: JAI. https://doi.org/10.1016/S0742-7301(06)25002-3

[19] H-F. Lin, (2007), "Knowledge sharing and firm innovation capability: an empirical study", International Journal of Manpower, 28 (3/4), pp.315-332. https://doi.org/10.1108/01437720710755272

[20] J.G. March, (1991), "Exploration and exploitation in organizational learning", Organization Science, 2(1), pp.71-87. https://doi.org/10.1287/orsc.2.1.71

[21] J. Ohehmichen, L.M.M. Heyden, D. Georgakakis, and H.W. Volberda (2017), "Boards of directors and organizational ambidexterity in knowledge-intensive firms", The International Journal of Human Resource Management, 28(.2), pp.283-306. https://doi.org/10.1080/09585192.2016.1244904

[22] P.M. Senge, (1990). The Fifth Discipline. New York: Doubleday.

[23] S.F. Slater and J. C. Naver (1995). 'Market orientation and the learning organization', Journal of Marketing, 59 (3), pp. 63-74. https://doi.org/10.2307/1252120

[24] S. Wang, and R.A. Noe (2010), « Knowledge sharing: A review and directions for future research », Human Resource Management Review, 20 , pp. $115-131$ https://doi.org/10.1016/j.hrmr.2009.10.001

[25] R.S. Yadav, (2015), "Linking various leadership styles to organizational innovation: A theoretical approach", Indor Management Journal, 5 (1), pp.30-42. 